\title{
Bariatric surgery and surgical devices in obesity management
}

\author{
CHINNADORAI RAJESWARAN, ${ }^{1}$ VINOD JOSEPH, ${ }^{1}$ MANISH KUSHE, ${ }^{1}$ ZAIDI ZULFIQAR, ${ }^{1}$ \\ DAVID MCLAREN, ${ }^{1}$ RHODRI KING, ${ }^{2}$ ROBERT RYDER ${ }^{3}$
}

\begin{abstract}
Obesity levels worldwide are reaching epidemic proportions with resultant strain on healthcare systems and individual wellbeing. To date, bariatric surgery is the management option that produces the greatest degree of weight loss which can be maintained in the long term along with a reduction in obesity-associated comorbidities such as diabetes and fewer cardiovascular events. Roux-en-Y gastric bypass, laparascopic gastric band and sleeve gastrectomy are the most widely performed bariatric procedures but, despite low perioperative mortality and complication rates, these procedures may not be suitable for all patients due to other factors. Newer surgical techniques are being developed both laparoscopically and endoscopically, in addition to the use of less invasive non-surgical devices that can achieve weight loss, by (1) increasing satiety such as gastric pacing and vagal nerve inhibition and ( 2 ) reducing absorption through aspiration of gastric contents, duodenal sheaths and thermal ablation of the duodenal mucosa. This article reviews current and future bariatric surgical procedures and introduces non-surgical devices that may increasingly feature in the management of obesity.

Br J Diabetes 2016:16:156-161
\end{abstract}

Key words: obesity, bariatric surgery, devices

\section{Background}

Obesity is a chronic condition that is increasing in prevalence in all age groups, and is now considered to be a global epidemic. ${ }^{1}$ The increase has been particularly high in England where prevalence has doubled over the last 25 years. In 2014 the WHO estimated that 1.9 billion adults worldwide were overweight and at

Mid-Yorkshire NHS Hospital Trust, UK

Leeds Institute for Cardiovascular and Metabolic Medicine, University of Leeds, UK

Sandwell and West Birmingham Hospitals, UK

Address for correspondence: Dr Chinnadorai Rajeswaran Consultant Physician in Diabetes, Obesity and Endocrinology, Dewsbury and District Hospital, Mid Yorkshire NHS Trust, Halifax Road, Dewsbury, West Yorkshire WF13 4HS, UK

Tel: +44 (0)1924816144

E-mail: chinnadorai.rajeswaran@midyorks.nhs.uk

http://dx.doi.org/10.15277/bjd.2016.104 least 600 million obese. By 2015 this is projected to rise to 2.3 billion and over 700 million, respectively. ${ }^{2}$

In most cases obesity results from an imbalance between energy input and expenditure. However, weight gain is multifactorial and may be due to identifiable and specific genetic defects (e.g. leptin deficiency, MC4 receptor mutations), damage to the hypothalamus (from trauma, tumours or surgery), drugs (e.g. antipsychotics) or life changing events (such as bereavement or separation). Short sleep duration, typically defined as having less than six hours of sleep, has also been associated with weight gain and obesity. ${ }^{3}$ The likely mechanisms could involve leptin, ghrelin hormones and possibly glucagon-like peptide-1 (GLP-1) as they affect satiety, hunger and food intake. ${ }^{4-6}$ Obesity is more prevalent in people with lower educational attainment, reduced employment prospects and lower socioeconomic status. ${ }^{7}$

Obesity is strongly associated with diabetes, the sex-specific prevalence increasing more than fivefold over the body mass index (BMI) range $15-50 \mathrm{~kg} / \mathrm{m}^{2}$ (from $2.8 \%$ to $11.4 \%$ for men; from $1.8 \%$ to $10.3 \%$ for women), most of this increase occurring above a BMI of $25 \mathrm{~kg} / \mathrm{m}^{2}{ }^{8}$ Estimates of the direct costs to the NHS for treating overweight and obese individuals, and related morbidity in England, have ranged from $\mathrm{f479.3}$ million in 1998 to $\mathrm{f4.2}$ billion in 2007. ${ }^{9}$ Estimates of the indirect costs (those costs arising from the impact of obesity on the wider economy such as loss of productivity) over the same time period ranged between $\mathrm{f2.6}$ billion ${ }^{10}$ and $\mathrm{f} 15.8$ billion. ${ }^{9}$

Bariatric surgery, which is presently the most effective treatment for obesity in terms of producing significant and sustained weight reduction, has provided compelling evidence that weight loss can ameliorate many obesity-related conditions and improve life expectancy. ${ }^{11-14}$ In 2007 a retrospective cohort study of obese subjects who were undergoing weight loss surgery showed a $40 \%$ reduction in all-cause mortality, a $92 \%$ reduction in diabetes deaths, a $56 \%$ reduction in coronary artery disease deaths and a $60 \%$ reduction in cancer deaths. ${ }^{15}$

\section{Current and future bariatric surgeries}

Non-surgical weight management including calorie restriction, exercise and/or medication generally achieves no more than a 5-10\% reduction in body weight. Recidivism after such weight loss exceeds $90 \%$ within 5 years. The disappointing results of these approaches have led to a burgeoning interest in bariatric surgery. ${ }^{16}$

Standard bariatric procedures

Traditionally, obesity surgery is considered appropriate for adult 
patients with a $\mathrm{BMI}>40 \mathrm{~kg} / \mathrm{m}^{2}$ or a BMl of $35-40 \mathrm{~kg} / \mathrm{m}^{2}$ with an obesity-related comorbidity. These selection criteria were developed in March 1991 by the National Institutes of Health Consensus Development Panel and have subsequently been adopted by all major surgical and non-surgical societies. ${ }^{17}$ Bariatric surgery is one of the fastest growing operative procedures performed worldwide, with an estimated $>340,000$ operations performed in 2011.18 Bariatric surgical procedures affect weight loss through two fundamental mechanisms: restriction of food intake and malabsorption. Adjustable gastric bands (AGB) and sleeve gastrectomy (SG) are restrictive procedures with reductions in BMl of $11.4 \mathrm{~kg} / \mathrm{m}^{2}$ and 16.7 $\mathrm{kg} / \mathrm{m}^{2}$ at 3 years, respectively. ${ }^{19}$ Gastric bypass (GB) surgery and biliopancreatic diversion/duodenal switch have both a restrictive and malabsorptive component generally resulting in greater weight loss with a reduction in BMl of $21.9 \mathrm{~kg} / \mathrm{m}^{2}$ at 3 years. ${ }^{19}$ This observed weight loss following bariatric surgery is associated with increased rates of remission of diabetes compared with controls, achieving $67.7 \%, 85.5 \%$ and $92.8 \%$ following AGB, SG, and GB respectively. Reduced incidence of diabetes $(96 \%, 84 \%$ and $78 \%$ at 2,10 and 15 years), myocardial infarction and stroke (adjusted hazard ratios or 0.71 and 0.66 ) have also been demonstrated in the Swedish Obesity Study (SOS). ${ }^{20}$

In addition to restriction and malabsorption of food, there are a number of other mechanisms which contribute to weight loss including alteration of gut microbiota, action on signalling between gut and brain and impact on gut hormones such as reduced orexigenic hormones such as ghrelin and increased anorectic hormones such as GLP-1 and peptide YY postprandially, which also aid insulin secretion and glucose control.21-30

\section{Newer surgical techniques}

Not all patients benefit from the above standard bariatric procedures and several newer surgical techniques have been developed, some of which are described below.

Primary Obesity Surgery Endoluminal (POSE) procedure: POSE is a minimally invasive incision-free endoscopic procedure wherein the stomach is folded in on itself. POSE is performed using a specialised endoscope inserted through the mouth. This procedure is performed under general anaesthesia and sutures are used to create new folds in the stomach, thereby reducing the capacity of the stomach. In a case series, 116 patients (79\% of total) who were available for follow-up at 1 year had a mean $45 \%$ excess weight loss. POSE was reported to be an effective, safe and well tolerated procedure; ${ }^{31}$ however, weight regain has limited its widespread use.

Laparoscopic Greater Curvature Plication (LGCP): This technique evolved from the Laparoscopic Sleeve Gastrectomy (LSG). In this procedure the stomach is folded in on itself and stitched into position to create a small stomach pouch which results in reducing the capacity of the stomach. The natural outlet of the stomach is maintained. The pouch is thought to be similar in form and function to that of a LSG, without the increased risks associated with cutting and stapling the stomach.
A retrospective study found a reduction of $82.1 \%$ in excess BMI at 12 months. ${ }^{32}$ However, in a meta-analysis comparing LGCP with LSG, LGCP was shown to result in significantly less weight loss than LSG and may in fact be associated with more adverse events over a 12-month period of follow-up. ${ }^{33}$ LGCP is an emerging and reversible technique sparing gastric resection and intestinal bypass. Its effectiveness is satisfactory for patients with $\mathrm{BMl}<45 \mathrm{~kg} / \mathrm{m}^{2}$ and the complication rate is acceptable. ${ }^{34}$

Band-on-Bypass (BoB): In patients who have started to regain weight after having gastric bypass surgery, BoB is an option if they cannot have a more complex surgery like biliopancreatic diversion or duodenal switch. It is adapted from the Fobi procedure whereby a silicon ring was placed around the gastric pouch at the same time as the primary bypass operation in an attempt to minimise weight regain and this is still performed by some centres. Adverse effects include increased reflux and vomiting leading to explantation of the ring. ${ }^{35}$

Laparoscopic one anastomotic gastric bypass (mini gastric bypass): First described at the turn of this century, the so called mini gastric bypass is gaining in popularity in established bariatric centres around the world. It was devised to be a quicker and safer alternative to conventional gastric bypass by having a single anastomotic site between a loop of jejunum and a lesser curvaturebased tube of stomach. It has attracted controversy, however, with concerns regarding increased biliary reflux, upper gastrointestinal cancers and increased complication rates. ${ }^{36}$ Weight loss appears to be similar to Roux-en-Y gastric bypass at around 38\% at 12 months, which is maintained at $30 \%$ after 9 years with similar rates of resolution of diabetes, sleep apnoea and hypertension also reported. 36,37 In experienced hands, operative time is reduced with no increased complication rates or ulceration. ${ }^{38}$

Single anastomosis duodeno-ileostomy (SADI): Similar to the mini gastric bypass, this procedure has been developed as a quicker and safer version of the biliopancreatic diversion or duodenal switch through the formation of a single anastomotic site between the duodenum and the ileum following a sleeve gastrectomy. Mean excess weight loss has been reported at around $100 \%$ at 3 years in a series of 50 patients, with improvements in metabolic parameters. Complication rates were low with two gastric leaks described and mild anaemia, hypoalbuminaemia and hypovitaminosis D noted in $10 \%, 25 \%$ and $40 \%$ of cases respectively at 3 years. ${ }^{39}$ The SADI may be an option when weight regain occurs following sleeve gastrectomy or in the super-obese due to its weight loss and potential for fewer complications, but long-term nutritional monitoring is still clearly required. Longer term follow-up and trials alongside established bariatric procedures are required to determine its true clinical utility.

\section{Devices}

The bariatric surgeries described above are associated with complications including anaesthetic risk during the procedure. Not 
Table 1 Summary of new therapeutic devices for the management of obesity

\begin{tabular}{|c|c|c|c|c|}
\hline Device (mode of action) & Trial type & Baseline BMI & Weight loss & Adverse events \\
\hline $\begin{array}{l}\text { VBLOC (increases satiety through } \\
\text { vagal nerve stimulation) }\end{array}$ & $\begin{array}{l}\text { Multi-centre } \\
\operatorname{RCT}^{40}(n=239)\end{array}$ & $\begin{array}{l}41 \mathrm{~kg} / \mathrm{m}^{2} \text { intervention } \\
\text { and sham group }\end{array}$ & $\begin{array}{l}\text { Mean EWL } 24.4 \% \text { (intervention) } \\
\text { vs. } 15.9 \% \text { (sham) } 12 \text { months }\end{array}$ & Dyspepsia, abdominal pain \\
\hline $\begin{array}{l}\text { Gastric pacemaker } \\
\text { (increases satiety) }\end{array}$ & $\begin{array}{l}\text { Single-centre } \\
\text { observational }{ }^{41} \\
(n=91)\end{array}$ & $41 \mathrm{~kg} / \mathrm{m}^{2}$ & $\begin{array}{l}\text { Mean EWL } 20 \% \text { at } 1 \text { year, } \\
25 \% \text { at } 2 \text { years }\end{array}$ & $\begin{array}{l}\text { Gastric penetration, lead } \\
\text { dislodgment }\end{array}$ \\
\hline $\begin{array}{l}\text { Duodeno-jejunal bypass liner } \\
\text { (reduces duodenal absorption } \\
\text { by minimising exposure of } \\
\text { food to duodenal mucosa) }\end{array}$ & $\begin{array}{l}\text { Single-centre } \\
\text { observational } \\
(n=165)\end{array}$ & $\begin{array}{l}53.5 \mathrm{~kg} / \mathrm{m}^{2} \\
(12 \text { week group) } \\
35.6 \mathrm{~kg} / \mathrm{m}^{2} \\
(6 \text { month group) } \\
35.1 \mathrm{~kg} / 2 \\
\text { (12 month group) }\end{array}$ & $\begin{array}{l}\text { Mean } 7 \% \text { (12 week group) } \\
10 \%(6,12 \text { month group) }\end{array}$ & $\begin{array}{l}\text { Gl bleeding, pancreatitis, } \\
\text { hepatic abscess }\end{array}$ \\
\hline
\end{tabular}

everyone will be suitable to undergo one of these surgical interventions for weight loss. In these patients a surgical device may be more appropriate, which is usually not associated with malabsorption and most of these procedures are reversible. Here we describe some of the devices currently being trialled (summarised in Table 1).

Vagal Nerve Block (VBLOC): The vagus nerve is involved in gastric acid and digestive enzyme secretion, gastric capacity, satiety and energy metabolism. The VBLOC procedure involves delivering high frequency electrical pulses intermittently to the vagus nerve using two laparoscopically implanted electrodes to lie adjacent to the vagus nerve at the lower portion of the oesophagus. A subcutaneous rechargeable neuroregulator device delivers a signal to the two electrodes. Given the intermittent nature of the block, it is thought that the nervous and digestive systems will not adapt and appetite will remain supressed. VBLOC therapy is a reversible procedure and does not alter the digestive anatomy.

The ReCharge randomised clinical trial is a randomised multicentre double-blind sham-controlled clinical trial involving 239 participants; 162 patients received an active vagal nerve block device and 77 received a sham device. All participants received weight management education. The 12-month blinded portion demonstrated that vagal nerve block resulted in a mean $24.4 \%$ excess weight loss compared with $15.9 \%$ in the sham group, which failed to achieve statistical significance $(p=0.71)$. The adverse events, which were more frequent in the vagal nerve block group, were dyspepsia and abdominal pain. VBLOC therapy was reported to be well tolerated, having met the primary safety objective. ${ }^{40}$
Implantable gastric pacing: This involves surgically implanting electric pacers into the stomach wall and then attaching the pacing wires to a generator placed in the subcutaneous tissue of the abdominal wall. ${ }^{41}$ Detection of food or drink entering the stomach results in delivery of a series of low-energy electrical impulses to the stomach, providing gastric stimulation that creates an early sensation of satiety. This feeling of fullness experienced by the patient reduces the desire to overeat or to eat between meals. The increased stimulation is thought to increase gastric motility, but it may also change fundal tone and alter gut hormone secretion. ${ }^{41}$

The level of gastric stimulation can be customised for patients based upon their individual needs. In the future this pacemaker may even have the ability to capture apnoeic episodes. Patients having a pacemaker will need support with behavioural changes. This is a minimally invasive and reversible procedure. As this procedure does not significantly alter the gastrointestinal tract anatomy, nutritional deficiency is not encountered, unlike other malabsorptive bariatric surgeries. The European LOSS (Laparoscopic Obesity Stimulation Survey) trial showed it to be a safe treatment with an approximate excess weight loss of $20 \%$ at 1 year. ${ }^{41}$ A review of gastric electrical pacing in 2014 found that, of 33 trials, significant results were found in appetite/satiety, gastric emptying rate, blood pressure and neurohormone levels or biochemical markers such as ghrelin or $\mathrm{HbA}_{1 c}$, respectively, and most studies observed significant weight loss at 12 months. Those with long-term follow-up such as the Transcend device group maintained significant weight loss. ${ }^{42}$

Aspire Assist A-Tube: The Aspire Assist Aspiration Therapy System consists of an endoscopically placed gastrostomy tube (percuta- 
neous endoscopic gastrostomy), A-tube and a siphon assembly. The Aspire Assist A-tube is during a gastroscopy performed under conscious sedation. After approximately 2 weeks of insertion, aspiration therapy is commenced. Patients are instructed to thoroughly chew food to aid aspiration and aspirate gastric contents 20 min after a meal, removing around $30 \%$ of calories consumed.

In a pilot study conducted by Sullivan et al this procedure was deemed to be safe and well tolerated. Patients in the intervention arm of the study lost about $50 \%$ of the excess weight loss compared with $15 \%$ excess weight loss in the control arm..$^{43} \mathrm{In}$ another study at 6 months $88 \%$ of the participants had a mean $41 \%$ of excess weight loss. ${ }^{44}$ Reported adverse events include abdominal discomfort and bloating, peristomal irritation, bleeding and infection and nausea.

This is a minimally invasive procedure and does not alter gastrointestinal tract anatomy, making it an alternative for obese patients who are reluctant to undergo bariatric surgery. The results of a European super-obese study $\left(\mathrm{BMl}>55 \mathrm{~kg} / \mathrm{m}^{2}\right)$ involving three centres and including 30 patients with an average BMI of $63 \mathrm{~kg} / \mathrm{m}^{2}$ are awaited. Although this procedure has been viewed with a lot of scepticism, there is a place for this procedure in the super-obese individual. Aspire Assist could be used either as a definitive therapy or as a bridge to standard bariatric surgery with the caveat that complication rates are likely to be greater.

Endoscopic gastrointestinal bypass devices: The EndoBarrier duodenal-jejunal bypass liner (DJBL) is a flexible collapsible $60 \mathrm{~cm}$ tube-like liner with a large proximal opening that is delivered endoscopically using a preloaded single-use device. Made from a durable polymer, the device is anchored in place with attached nitinol (alloy of nickel and titanium) points that adhere and secure the liner to the wall of the duodenum. The device is delivered endoscopically under general anaesthesia or moderate sedation during a procedure that takes on average about $30 \mathrm{~min}$.

The EndoBarrier liner creates a physical barrier between ingested food and the proximal intestine, mimicking the duodenal-jejunal exclusion of Roux-en-Y gastric bypass. Clinical data suggest that the EndoBarrier works by affecting key hormones involved in insulin sensitivity, glucose metabolism, satiety and food intake. ${ }^{45}$ It is a relatively safe procedure, but the reported early removal rate due to patient intolerance or side effects is $10-20 \%$ in clinical trials outside the USA. ${ }^{46}$

Two recent studies have reported that the duodeno-jejunal bypass liner has a reasonable safety and tolerability profile and was associated with $10-20 \%$ reduction in body weight, depending on duration of implantation of the device (12 weeks, 6 months and 12 months), along with some improvements in metabolic parameters. ${ }^{47,48}$ Post-procedure, many patients experience abdominal discomfort, mild to moderate pain and/or nausea, with more serious complications including device migration, gastrointestinal bleeding, perforation, obstruction, hepatic abscess, pancreatitis and cholecystitis.46-48 Patient selection, expert use of the device at placement and removal, and the supportive care of an experienced multidisciplinary clinical team are key for safe and effective use of the DJBL.

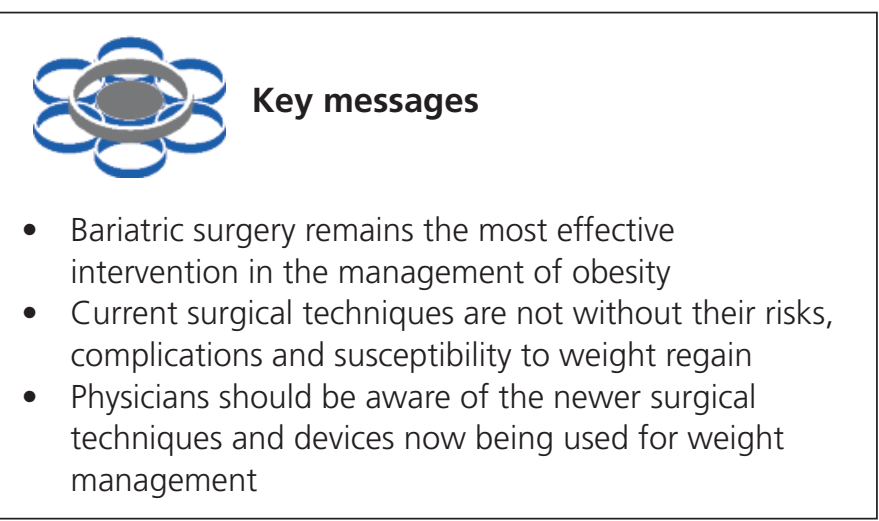

In July 2015 a US study comparing the EndoBarrier with a sham procedure, the ENDO trial, was terminated early having recruited 325 of 500 patients due to concerns regarding the rate of hepatic abscess $(n=7$, incidence rate $3.2 \%)$, exceeding the safety threshold of $2 \%$. The reason for the increased incidence of hepatic abscess in the trial compared with global figures $\left(0.73 \%\right.$ from 3,000 patients) is unclear, but a reduction in $\mathrm{HbA}_{1 \mathrm{c}}$ of $1.1 \%$ at 12 months illustrates the potential clinical utility of the EndoBarrier if its safety profile can be improved. ${ }^{49}$

Intragastric balloon: The endoscopic placement of a balloon into the stomach to achieve weight loss by increasing satiety and reducing food intake has been recognised for several decades. A meta-analysis in 2013 reported $8.9 \mathrm{~kg}$ greater weight loss following 6 months of balloon placement compared with controls, with around $10 \%$ weight loss maintained at 1 year (6 months following balloon removal) in some studies and $50 \%$ remission of metabolic syndrome. ${ }^{46,50,51}$ Adverse events such as nausea, vomiting and abdominal pain occurred much more frequently in the intervention group, along with gastric erosions and ulceration. Intragastric balloons are capable of producing clinically meaningful weight loss in the short term, but concerns exist regarding weight regain in the long term and therefore may be better placed as a bridge to bariatric surgery in high-risk individuals. ${ }^{46}$

Duodenal Mucosal Resurfacing (DMR): This novel minimally invasive technique is predominantly aimed at improving glycaemic control and is currently entering phase I clinical trials. ${ }^{52}$ Promising results from a proof of concept study were reported at the 3rd World Congress on Interventional Therapies for Type 2 Diabetes in September 2015. Thermal ablation is employed to alter the duodenal mucosal surface with an improvement noted in $\mathrm{HbA}_{1 c}$ from $8.5 \%$ to $7.1 \%$ at 6 months in patients who received treatment on a long segment $(>9 \mathrm{~cm})$ and was associated with a modest $2.3 \mathrm{~kg}$ reduction in body weight. Complications included duodenal stenosis $(7-8 \%, n=3)$ and thus the results of larger clinical trials are awaited with interest.

\section{Conclusion}

Bariatric surgery remains the most effective intervention in the management of obesity in terms of weight reduction, resolution of co- 
morbidities and improved mortality. Current surgical techniques are not without their risks, complications and susceptibility to weight regain, so it is important that they continue to be refined and challenged as our understanding of their underlying physiological effects improves. Surgery, however, is not the panacea of treatment, and the development of less invasive non-surgical techniques is important to assist physicians in the struggle against the relentless tsunami of obesity and diabetes. Further research is required to determine the efficacy and safety of these procedures before widespread implementation.

\section{Conflict of interest None. Funding None.}

\section{References}

1. Finkelstein EA, Trogdon JG, Cohen JW, et al. Annual medical spending attributable to obesity: payer-and service-specific estimates. Health Aff (Millwood) 2009;28:w822. http://dx. doi.org/10.1377/hlthaff.28.5.w822

2. World Health Organization. Factsheet number 311. Obesity and overweight. www.who.int/mediacentre/factsheets/fs311/en/index.html (accessed July 2015)

3. Patel SR. Reduced sleep as an obesity risk factor. Obes Rev 2009;10(Suppl 2):61-8 http://dx.doi.org/10.1111/j.1467-789X.2009.00664.x

4. Taheri S, Lin L, Austin D, et al. Short sleep duration is associated with reduced leptin, elevated ghrelin, and increased body mass index. PLoS Med 2004;1:e62. http://dx.doi.org/10.1371/journal.pmed.0010062

5. Spiegel K, Tasali E, Penev P, et al. Brief communication: sleep curtailment in healthy young men is associated with decreased leptin levels, elevated ghrelin levels, and increased hunger and appetite. Ann Intern Med 2004; 141:846-50. http://dx.doi.org/10.7326/0003-4819-141-11-20041207000008

6. St-Onge MP, O'Keeffe M, Roberts AL, et al. Short sleep duration, glucose dysregulation and hormonal regulation of appetite in men and women. Sleep 2012;35:1503-10. http://dx.doi.org/10.5665/sleep.2198

7. Public Health England Obesity. www.NOO.org.uk (accessed July 2015).

8. Health and Social Care Information Centre. The Health Survey for England 2006. London.

9. Butland B, Jebb S, Kopelman P, et al. Tackling obesities: future choices - project report (2nd Ed). London: Foresight Programme of the Government Office for Science, 2007.

10. National Audit Office. Tackling obesity in England. London: The Stationery Office, 2001 (accessed July 2015).

11. Adams TD, Stroup AM, Gress RE, et al. Cancer incidence and mortality after gastric bypass surgery. Obesity (Silver Spring) 2009;17:796-802. http://dx.doi.org/10.1038/oby.2008.610

12. Brancatisano A, Wahlroos S, Matthews S, et al. Gastric banding for the treatment of type 2 diabetes mellitus in morbidly obese. Surg Obes Relat Dis 2008;4:423-9. http://dx.doi.org/10.1016/j.soard.2007.10.011

13. Busetto L, Mirabelli D, Petroni ML, et al. Comparative long-term mortality after laparoscopic adjustable gastric banding versus nonsurgical controls. Surg Obes Relat Dis 2007;3:496-502. http://dx.doi.org/10.1016/j.soard.2007.06.003

14. Sjostrom L, Narbro K, Sjostrom CD, et al. Effects of bariatric surgery on mortality in Swedish obese subjects. N Engl J Med 2007;357:741-52. http://dx.doi.org/10.1056/NEJMoa066254

15. Adams TD, Gress RE, Smith SC, et al. Long-term mortality after gastric bypass surgery. N Engl J Med 2007;357:753-61. http://dx.doi.org/10.1056/NEJMoa066603

16. Solomon CG, Dluhy RG. Bariatric surgery: quick fix or long-term solution? N Engl J Med 2004;351:2751-3. http://dx.doi.org/10.1056/NEJMe048308

17. Korenkov M, Sauerland $S$, Junginger T. Disclosures surgery for obesity. Curr Opin Gastroenterol 2005;21:679-83.

18. Buchwald H, Oien DM. Metabolic/bariatric surgery worldwide 2011. Obes Surg 2013;23:427-36. http://dx.doi.org/10.1007/s11695-012-0864-0
19. Chang SH, Stoll CR, Song J, Varela JE, Eagon CJ, Colditz GA. The effectiveness and risks of bariatric surgery: an updated systematic review and meta-analysis, 2003-2012. JAMA Surg 2014;149:275-87. http://dx.doi.org/10.1001/jamasurg.2013.3654

20. Sjostrom L. Review of the key results from the Swedish Obese Subjects (SOS) trial: a prospective controlled intervention study of bariatric surgery. J Intern Med 2013;273:219-34. http://dx.doi.org/10.1111/joim.12012

21. Lim RB, Blackburn GL, Jones DB. Benchmarking best practices in weight loss surgery. Curr Prob/ Surg 2010;47:79-174. http://dx.doi.org/10.1067/j.cpsurg.2009.11.003

22. Tritos NA, Mun E, Bertkau A, et al. Serum ghrelin levels in response to glucose load in obese subjects post-gastric bypass surgery. Obes Res 2003;11:919-24. http://dx.doi.org/10.1038/oby.2003.126

23. Cummings DE, Weigle DS, Frayo RS, et al. Plasma ghrelin levels after diet-induced weight loss or gastric bypass surgery. N Engl J Med 2002;346:1623-30. http://dx.doi.org/10.1056/NEJMoa012908

24. Korner J, Bessler M, Cirilo LJ, et al. Effects of Roux-en-Y gastric bypass surgery on fasting and postprandial concentrations of plasma ghrelin, peptide YY, and insulin. J Clin Endocrinol Metab 2005;90:359-65. http://dx.doi.org/10.1210/jc.2004-1076

25. Karamanakos SN, Vagenas K, Kalfarentzos F, et al. Weight loss, appetite suppression, and changes in fasting and postprandial ghrelin and peptide-YY levels after Roux-en-Y gastric bypass and sleeve gastrectomy: a prospective, double blind study. Ann Surg 2008;247:401-07. http://dx.doi.org/10.1097/SLA.0b013e318156f012

26. le Roux CW, Aylwin SJ, Batterham RL, et al. Gut hormone profiles following bariatric surgery favor an anorectic state, facilitate weight loss, and improve metabolic parameters. Ann Surg 2006;243:108-14. http://dx.doi.org/10.1097/01.sla.0000183349.16877.84

27. Rubino F, Gagner M, Gentileschi P, et al. The early effect of the Rouxen-Y gastric bypass on hormones involved in body weight regulation and glucose metabolism. Ann Surg 2004;240:236-42. http://dx.doi.org/10.1097/01.sla.0000133117.12646.48

28. Roth $\mathrm{CL}$, Reinehr T, Schernthaner GH, et al. Ghrelin and obestatin levels in severely obese women before and after weight loss after Roux-en-Y gastric bypass surgery. Obes Surg 2009;19:29-35. http://dx.doi.org/10.1007/s11695-008-9568-x

29. Greiner T, Bäckhed F. Effects of the gut microbiota on obesity and glucose homeostasis. Trends Endocrinol Metab 2011:22:117-23. http://dx.doi.org/10.1016/j.tem.2011.01.002

30. Meek CL, Lewis HB, Reimann F, Gribble FM, Park AJ. The effect of bariatric surgery on gastrointestinal and pancreatic peptide hormones. Peptides 2016;77:28-37. http://dx.doi.org/10.1016/j.peptides.2015.08.013

31. López-Nava G, Bautista-Castaño I, Jimenez A, et al. The Primary Obesity Surgery Endolumenal (POSE) procedure: one-year patient weight loss and safety outcomes. Surg Obes Relat Dis 2015;11:861-5. http://dx.doi.org/10.1016/j.soard.2014.09.026.

32. Kim SB, Kim KK, Chung JW, et al. Initial experiences of laparoscopic gastric greater curvature plication in Korea: a review of 64 cases. J Laparoendosc Adv Surg Tech A 2015;25:793-9. http://dx.doi.org/10.1089/lap.2015.0164

33. Tang Y, Tang S, Hu S. Comparative efficacy and safety of laparoscopic greater curvature plication and laparoscopic sleeve gastrectomy: a metaanalysis. Obes Surg 2015;25:2169-75. http://dx.doi.org/10.1007/s11695-015-1842-0

34. Skrekas G, Antiochos K, Stafyla VK. Laparoscopic gastric greater curvature plication: results and complications in a series of 135 patients. Obes Surg 2011:21:1657-63. http://dx.doi.org/10.1007/s11695-011-0499-6

35. Rasera I Jr, Coelho TH, Ravelli MN, et al. A comparative, prospective and randomized evaluation of Roux-en-Y gastric bypass with and without the silastic ring: a 2-year follow up preliminary report on weight loss and quality of life. Obes Surg 2016;26:762-8 http://dx.doi.org/10.1007/s11695-015-1851-z

36. Mahawar KK, Jennings N, Brown J, Gupta A, Balupuri S, Small PK. "Mini" gastric bypass: systematic review of a controversial procedure. Obes Surg 2013:23:1890-8.

http://dx.doi.org/10.1007/s11695-013-1026-8

37. Lee WJ, Ser KH, Lee YC, Tsou JJ, Chen SC, Chen JC. Laparoscopic Rouxen-Y vs. mini-gastric bypass for the treatment of morbid obesity: a 10- 
year experience. Obes Surg 2012;22:1827-34 http://dx.doi.org/10.1007/s11695-012-0726-9

38. Parmar CD, Mahawar KK, Boyle M, et al. Mini Gastric Bypass: first report of 125 consecutive cases from United Kingdom. Clin Obes 2016;6:61-7. http://dx.doi.org/10.1111/cob.12124

39. Sanchez-Pernaute A, Herrera MA, Perez-Aguirre ME, et al. Single anastomosis duodeno-ileal bypass with sleeve gastrectomy (SADI-S). One to three-year follow-up. Obes Surg 2010;20:1720-6. http://dx.doi.org/10.1007/s11695-010-0247-3.

40. Ikramuddin S, Blackstone RP, Brancatisano A, et al. Effect of reversible intermittent intra-abdominal vagal nerve blockade on morbid obesity: the ReCharge randomized clinical trial. JAMA 2014;312:915-22. http://dx.doi.org/10.1001/jama.2014.10540

41. Miller K, Hoeller E, Aigner F. The implantable gastric stimulator for obesity: an update of the European experience in the LOSS (Laparoscopic Obesity Stimulation Survey) study. Treat Endocrinol 2006;5:53. http://dx.doi.org/10.2165/00024677-200605010-00006

42. Cha R, Marescaux J, Diana M. Updates on gastric electrical stimulation to treat obesity: Systematic review and future perspectives. World $J$ Gastrointest Endosc 2014;6:419-31. http://dx.doi.org/10.4253/wjge.v6.i9.419

43. Sullivan $S$, Stein $R$, Jonnalagadda $S$, et al. Aspiration therapy leads to weight loss in obese subjects: a pilot study. Gastroenterology 2013;145:1245-52. http://dx.doi.org/10.1053/j.gastro.2013.08.056

44. Forssell $H$, Norén $E$. A novel endoscopic weight loss therapy using gastric aspiration: results after 6 months. Endoscopy 2015;47:68-71. http://dx.doi.org/10.1055/s-0034-1378097

45. de Jonge C, Rensen SS, Verdam FJ, et al. Endoscopic duodenal-jejunal bypass liner rapidly improves type 2 diabetes. Obes Surg 2013;23:1354-60. http://dx.doi.org/10.1007/s11695-013-0921-3

46. Majumder S, Birk J. A review of the current status of endoluminal therapy as a primary approach to obesity management. Surg Endosc 2013;27:2305-11. http://dx.doi.org/10.1007/s00464-012-2765-7

47. Escalona A, Pimentel F, Sharp A, et al. Weight loss and metabolic improvement in morbidly obese subjects implanted for 1 year with an endoscopic duodenal-jejunal bypass liner. Ann Surg 2012;255:1080-5. http://dx.doi.org/10.1097/SLA.0b013e31825498c4

48. Betzel B, Koehestanie P, Aarts EO, et al. Safety experience with the duodenal-jejunal bypass liner: an endoscopic treatment for diabetes and obesity. Gastrointest Endosc 2015;82:845-52. http://dx.doi.org/10.1016/j.gie.2015.03.1911

49. GI Dynamics. Data as of 30 June 2015.

50. Zheng $Y$, Wang M, He S, Ji G. Short-term effects of intragastric balloon in association with conservative therapy on weight loss: a meta-analysis. J Transl Med 2015:13:246.

http://dx.doi.org/10.1186/s12967-015-0607-9

51. Fuller NR, Pearson S, Lau NS, et al. An intragastric balloon in the treatment of obese individuals with metabolic syndrome: a randomized controlled study. Obesity 2013:21:1561-70. http://dx.doi.org/10.1002/oby.20414

52. www.clinicaltrials.gov/ct2/show/NCT02413567 (accessed January 2016)

\section{ACCU-CHEK}

Sometimes

there are only good choices.

DISCREET

REMOTE CONTROL PUMP TECHNOLOGY

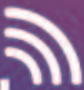

\section{Y}

. 